\title{
Catalytic Hydroisomerization Upgrading of Vegetable Oil-Based Insulating Oil
}

\author{
Dieu-Phuong Phan and Eun Yeol Lee* \\ Department of Chemical Engineering, Kyung Hee University, Gyeonggi-do 17104, Korea; \\ phanphuong07h5@gmail.com \\ * Correspondence: eunylee@khu.ac.kr; Tel.: +82-31-201-3839
}

Received: 9 February 2018; Accepted: 28 March 2018; Published: 28 March 2018

\begin{abstract}
Due to its high biodegradability, high dielectric strength, and good thermal stability, vegetable oil is under consideration as an alternative transformer fluid for power system equipment, replacing traditional petroleum-based insulating oils. Its main drawbacks are its poor low-temperature properties arising from the crystallization of its long-chain normal paraffins, and its lower oxidative stability arising from its higher concentration of unsaturated fatty acids. Hydroisomerization/isomerization over bifunctional catalysts is considered to be an efficient pathway to upgrade vegetable oil-based insulating oil; this converts saturated/unsaturated long-chain fatty acids to branched isomers. The efficiency of this process depends crucially on the behavior of the catalyst system. This paper extensively reviews recent results on the influence that the metal phase and acidity, the effects of pore channels, and the balance between metal and acid sites have upon the activity and selectivity of catalytic hydroisomerization.
\end{abstract}

Keywords: insulating oils; hydroisomerization; bio-insulating oil; zeolite

\section{Introduction}

\subsection{Importance of Biologically Sourced Insulating Oil}

Insulating oils are liquid dielectrics that are extensively used in transformers, one of the most important pieces of equipment in the power system. The important functions of transformer oil are to ensure electrical insulation and to act as a cooling fluid, removing heat from the windings and the core [1]; thus, the oil determines the life span of the equipment. Petroleum-based oils, also called mineral oils, have been used as transformer oils since the 1880s due to their good compatibility with cellulose paper insulation, suitable physicochemical and heat dissipation properties, and low cost [2]. However, these oils have many negative aspects including their non-renewability, low flash point, and low fire point, as well as the various environmental, political, and socioeconomic issues associated with petroleum products. Polychlorinated aromatic hydrocarbon fluids (such as Polychlorinated Biphenyls-PCBs), silicones, and synthetic ester fluids have been used as alternative fluids thanks to their outstanding properties such as higher fire points compared to mineral oil and good oxidative and thermal stabilities. However, their availability and comparatively higher cost have confined their application to special transformers [3,4]. Furthermore, these oils are poorly biodegradable, flammable, and have negative environmental impacts, since equipment failure and leakage can contaminate soil and water.

Vegetable oils, which are natural esters, are considered to be promising candidates for insulating oils owing to their high biodegradability, good thermal properties, and wide availability $[5,6]$. The use of vegetable oil-based insulating oil could resolve environmental problems thanks to their high biodegradability and lack of toxicity in nature. Moreover, vegetable oils are less expensive than 
synthetic esters, and in the long run may be even cheaper than mineral oil. In addition, owing to their hydrophilicity, vegetable-based insulating oil could increase the life of transformers compared to conventional mineral oils (Table 1).

Table 1. Properties of typical transformer dielectric fluids (modified from Reference [7]).

\begin{tabular}{|c|c|c|c|c|}
\hline & Mineral Oils & Silicone Oils & Synthetic Esters & Vegetable Oils \\
\hline Kinematic viscosity at $0^{\circ} \mathrm{C}$, centistokes-cSt & $<76$ & $81-92$ & $26-240$ & $77-500$ \\
\hline at $100{ }^{\circ} \mathrm{C}$ & $2-3$ & $15-17$ & $4-6$ & $4-15$ \\
\hline Pour point, ${ }^{\circ} \mathrm{C}$-ASTM D97 & -30 to -60 & -50 to -60 & -40 to -60 & -10 to -33 \\
\hline Flash point, ${ }^{\circ} \mathrm{C}$-ASTM D92 & $110-175$ & $300-310$ & $250-310$ & $310-343$ \\
\hline Biodegradability over 21 days - CEC-L-33 & $<30 \%$ & $0 \%$ & $80 \%$ & $97 \%-99 \%$ \\
\hline Specific heat, $\mathrm{J} \cdot \mathrm{g}^{-1} \cdot \mathrm{k}^{-1}$ & $1.6-2.0$ & 1.5 & $1.8-2.3$ & $1.5-2.1$ \\
\hline Water solubility, ppm, at $20^{\circ} \mathrm{C}$ & 45 & 200 & 2700 & \\
\hline at $100^{\circ} \mathrm{C}$ & 650 & 1100 & 7200 & \\
\hline Expansion coefficient, $10^{-4} \mathrm{k}^{-1}$ & $7-9$ & 10 & $6.5-10$ & $5.5-5.9$ \\
\hline
\end{tabular}

The main fatty esters present in biologically sourced insulating oil (hereinafter 'vegetable oil-based insulating oil') are palmitic acid (C16:0), stearic acid (18:0), oleic acid (18:1), linoleic acid (18:2), and linolenic acid (18:3). This applies to oils from various biomass feedstocks, as listed in Table 2, including soybean, sunflower, rapeseed (i.e., canola), palm, and peanut oils. Various other fatty acids are present in minor amounts in virtually all oils and fats derived from bio-oil feedstocks. 
Table 2. Fatty acid compositions of various vegetable oils (modified from Reference [8]).

\begin{tabular}{|c|c|c|c|c|c|c|c|c|c|c|c|c|c|}
\hline & Fatty Acid & & Microalgae (Sp) & Palm & Olive & Peanut & Rape-Seed & Soybean & Sunflower & Grape & Almond & Corn & Coconu \\
\hline \multirow{7}{*}{ Saturated } & Capric & C10:0 & - & - & - & - & - & - & - & - & - & - & 6.0 \\
\hline & Lauric & C12:0 & - & 0.1 & - & 0.1 & - & - & - & - & - & - & 47.0 \\
\hline & Myristic & C14:0 & 0.3 & 0.7 & - & 0.1 & - & - & - & 0.1 & - & - & 18.0 \\
\hline & Palmitic & C16:0 & 40.2 & 36.7 & 11.6 & 8.0 & 4.9 & 11.3 & 6.2 & 4.6 & 10.4 & 6.5 & 9.0 \\
\hline & Stearic & C18:0 & 1.2 & 6.6 & 3.1 & 1.8 & 1.6 & 3.6 & 3.7 & 3.4 & 2.9 & 1.4 & 3.0 \\
\hline & Arachidic & C20:0 & 0.1 & 0.4 & 0.03 & 0.9 & - & 0.3 & 0.3 & 0.3 & 0.3 & 0.1 & - \\
\hline & Behenic & $\mathrm{C} 22: 0$ & - & 0.1 & 0.1 & 3 & - & - & 0.7 & 0.7 & 0.1 & - & - \\
\hline \multirow{4}{*}{ Mono-unsaturated } & Palmitoleic & C16:1 & 9.2 & - & - & - & - & - & - & - & - & - & - \\
\hline & Oleic & C18:1 & 5.4 & 46.1 & 75.0 & 53.3 & 33.0 & 24.9 & 25.2 & 62.8 & 77.1 & 65.6 & 6.0 \\
\hline & Gadoleic & C20:1 & - & 0.2 & - & 2.4 & 9.3 & 0.3 & 0.2 & - & - & 0.1 & - \\
\hline & Erucic & C22:1 & - & - & - & - & 23.0 & 0.3 & 0.1 & - & - & 0.1 & - \\
\hline \multirow{2}{*}{ Poly-unsaturated } & Linoleic & C18:2 & 17.9 & 8.6 & 7.8 & 28.4 & 20.4 & 53.0 & 63.1 & 27.5 & 7.6 & 25.2 & 2.0 \\
\hline & Linolenic & C18:3 & 18.3 & 0.3 & 0.6 & 0.3 & 7.9 & 6.1 & 0.2 & 0.1 & 0.8 & 0.1 & - \\
\hline
\end{tabular}

Sp: Spirulina maxima. 


\subsection{Application Drawbacks of Vegetable Oil-Based Insulating Oils}

Although vegetable oil-based insulating oils have various advantages as discussed above, they also have the drawbacks of high pour points, higher viscosity, and poorer aging compared to conventional mineral oils [9-11]. For instance, the pour points of common vegetable esters are in the range from -10 to $-33{ }^{\circ} \mathrm{C}$ due to their higher contents of long-chain normal paraffins compared to mineral oils, which can be a critical problem for low-temperature applications [12]. However, the structural properties of acid chain length, unsaturation, and branching can be altered to tailor the pour points of vegetable oil-based insulating oils.

Secondly, under normal transformer operating temperatures, vegetable oil-based insulating oils show higher viscosities than mineral oils, meaning that they will yield less efficient convection heat transfer and thus higher operation temperatures. Moreover, viscosity strongly influences the impregnation of cellulose-based solid insulation. It has been observed that with natural esters it takes at least two times as long to complete the impregnation of laminated pressboard. This process can be hastened by carrying it out at a slightly higher temperature [13].

Liquid insulators used in transformers must show higher stabilities toward oxidation. Oxidation is the most influential factor in oil aging, and is especially important for oils used in free-breathing transformers [11]. Actually, the oxidative stabilities of natural esters depend on their fatty acid distributions, the refining processes used, and the presence of natural antioxidants. It is known that increasing the unsaturated fatty acid content decreases the oxidative stability of natural esters. For example, the oxidation stability of oleic acid (having one double bond) is 10 times that of linoleic acid (having two double bonds), which is in turn twice that of linolenic acid (having three double bonds).

Solving these problems simultaneously has been challenging because solving one problem often worsens another. The properties of vegetable oil-based insulating oils depend mainly on the structures of their constituent fatty acids. Hence, the properties of these esters can be tailored by choosing a suitable ratio of saturated to unsaturated triglycerides during their formulation. Branched-chain saturated fatty acids are ideal components because they have better low-temperature properties than linear saturated fatty acid and show greater oxidative stability than linear unsaturated fatty acids [14].

The aim of this review is to summarize recent processes to produce high-quality insulating oils from renewable sources. We focus on catalytic processes to transform the normal long-chain hydrocarbons of fatty acids to branched isomers that are desirable components for vegetable oil-based insulating oils and bio-fuel oils in general.

\section{Catalytic Hydroisomerization/Isomerization of Long-Chain Saturated/Unsaturated Fatty Acids}

\subsection{Hydroisomerization/Isomerization for Upgrading Vegetable Oil-Based Insulating Oils}

In the pathway of vegetable oil-based insulating oil upgrading, catalytic hydroisomerization is a more sustainable process for reducing the concentration of linear paraffins by transforming them to their branched isomers. According to Abhari et al. [15], the pour point of vegetable oil was decreased to $-10^{\circ} \mathrm{C}$ by applying the hydroisomerization over $\mathrm{Pt} / \mathrm{Pd}$ on an amorphous silica/alumina catalyst. The hydroisomerized product had the iso-paraffin to $n$-paraffin ratio in the range of 1:1 to 10:1, of which about $80 \%$ were mono-methyl branched paraffins. Reaume et al. $[16,17]$ showed that the synergetic use of hydroisomerization and isomerization can decrease the cloud points (defined as the temperature at which the oil becomes cloudy) of oleic methyl ester, palmitic methyl ester, and various natural esters by 7.5 to $12.9^{\circ} \mathrm{C}$. Isomerization is used to convert unsaturated fatty acids already having $\mathrm{C}=\mathrm{C}$ bonds, whereas hydroisomerization is used to introduce these $\pi$ bonds into saturated chains (creating a carbon-carbon double bond site), which requires a dehydrogenation/hydrogenation step. Firstly, the dehydrogenation of normal paraffins takes place over a metal phase. The generated olefins diffuse and protonate on the Brønsted acid sites to form alkylcarbenium ions, which then undergo skeletal isomerization and then deprotonation by means of beta scission. After desorbing from acid sites and 
diffusing to metal sites, these isomerized olefins are then hydrogenated to form the corresponding paraffins [18]. The desired and undesired products of these reactions are shown in Figure 1. These two different reactions are thus indispensable to improve the low-temperature properties of insulating and lubricant oils.
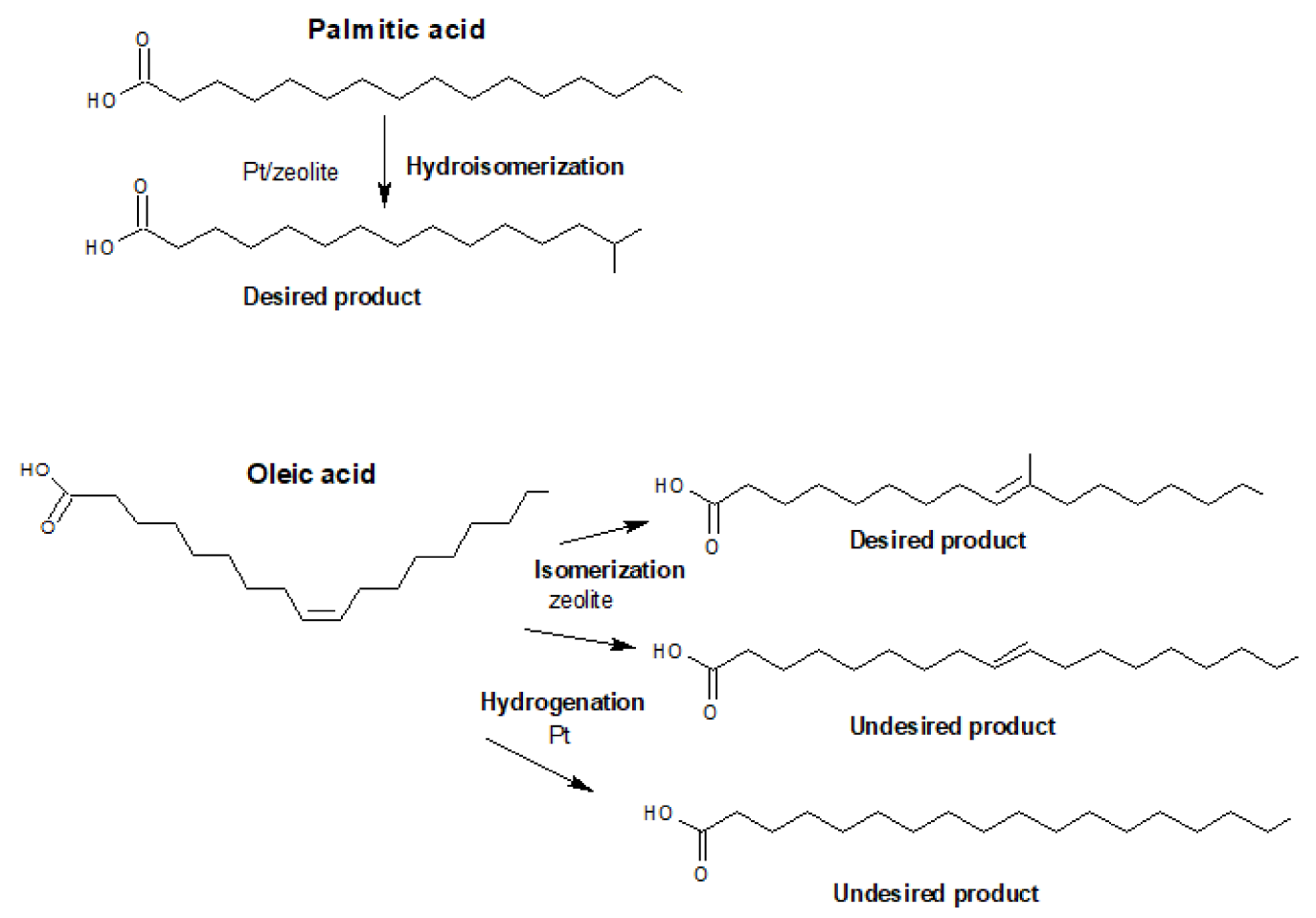

Figure 1. Desired and undesired products from the isomerization/hydroisomerization of oleic acid and the hydroisomerization of palmitic acid (modified from Reference [16]).

Because they allow a combination of dehydrogenation/hydrogenation and acid catalysis that is highly desirable for bio-oil upgrading, bifunctional metal/acid catalysts have attracted the attention of many researchers worldwide, who have explored their special catalytic performance and worked to elucidate their mechanisms $[16,17,19-26]$. Various catalysts have been reported for $n$-paraffin transformation, with a wide range of performance depending upon reaction temperature, metal site types, acidity, support structure effects, and the balance between metal and acid sites. Generally, an effective bifunctional catalyst for hydroisomerization should diminish side reactions such as hydrocracking and oligomerization. The decomposition of carbocations during hydrocracking occurs by means of beta scission of $\mathrm{C}-\mathrm{C}$ bonds, the selectivity of which depends on the natural and structural effects of acid sites in the catalyst support. According to Coonradt and Garwood [27], these differences in selectivity arise from catalysts' differences in acidity and relative strengths of dehydrogenation/hydrogenation activity. The balance between metal and Brønsted acid sites plays a vital role in determining the selectivity of the catalyst; high metal site density limits the formation of multiply branched isomers by promoting hydrogenation of the primary isomerization products, an issue that has received relatively little attention, with only a few reports so far [28]. Metal dispersion, metal loading, acidity and density of acid sites, and porous channel system effect are also key properties for determining the catalyst selection and experimental design [29-32]. 


\subsection{Catalyst System for Hydroisomerization/Isomerization}

\subsubsection{Metallic Function}

The metal phase type is important to the catalytic performance. Both noble metals (Pt, Pd, etc.) and non-noble metal catalysts $(\mathrm{Ni}, \mathrm{Co}, \mathrm{Cu}$, etc.) have been found to be efficient metallic catalysts for normal long-chain paraffin hydroisomerization [22]. Compared to non-noble metal types, noble metal catalysts show considerably higher activity and selectivity for hydroisomerization due to their easy activation of hydrogen, which then spills over onto the surface of support [33]. Zhang et al. [21] evaluated the role of the metal phase upon the catalytic performance of tungstenated zirconia for $n$-hexadecane transformation; among the different metals they evaluated ( $\mathrm{Pd}, \mathrm{Pt}$, and $\mathrm{Ni})$, with varying metal loadings in one case, platinum was found to be the best for the metallic phase. Metal content is also a key factor for tailoring the catalytic performance of supported metal catalysts. Song et al. [30] investigated the effect of Pd loading upon the catalytic performance of $n$-decane hydroisomerization over a Pd-based catalyst supported on SAPO-11 zeolite in a fixed-bed continuous microreactor. The metal dispersion on SAPO-11 decreased with increasing Pd loading, owing to the increasing agglomeration of metal particles on the support surface. Additionally, increasing the metal particle size can partially block some pore mouths of SAPO-11, impairing its function as a molecular sieve and thereby dramatically increasing the ratio between the density of accessible Pd metal sites and the number of available Brønsted acid sites. For $n$-decane hydroisomerization, the activity of $\mathrm{xPd} / \mathrm{SAPO}-11$ catalyst decreases in order of decreasing metal dispersion according to the following trend: $0.1 \mathrm{Pd} / \mathrm{SAPO}-11>0.3 \mathrm{Pd} / \mathrm{SAPO}-11>0.05 \mathrm{Pd} / \mathrm{SAPO}-11>0.5 \mathrm{Pd} / \mathrm{SAPO}-11$. The lower activity of the catalyst, having the lowest Pd content, is due to its deficiency of metal sites; in this case of low $\mathrm{Pd}$ loading, the rate of the transformation is limited by the rate of hydrogenation/dehydrogenation over the Pd sites.

Frank Bauer et al. [34] focused on the hydroisomerization of $n$-hexadecane over nanosized bimetallic Pt-Pd/H-Beta catalysts, finding that the Pt/H-beta catalyst is significantly more selective for hydroisomerization than its Pd-containing counterparts, owing to the higher hydrogenating activity of Pt relative to $\mathrm{Pd}$. On the other hand, the metal dispersion and bimetallic interaction play important roles in the hydroisomerization activity. In fact, Bauer et al. found that the branched isomer selectivity was superior to $90 \%$ at the conversion of $64.8 \%$ over the $\mathrm{Pt} / \mathrm{H}$-beta catalyst. With gradual increasing in the loading of $\mathrm{Pd}$ as a promoter, the hydroisomerization activity remarkably increased due to increasing noble metal dispersion, specifically as a result of increasing the concentration of the easily reducible palladium oxides present after calcination, which promote hydroisomerization [34,35] (Table 3).

Table 3. Metal dispersion, $n$-hexadecane conversion, and isomerized selectivity/cracked selectivities of Pd-Pt/H-Beta catalysts with various $\mathrm{Pt}$ and Pd loadings. Reaction conditions: $\mathrm{T}=200{ }^{\circ} \mathrm{C}, \mathrm{P}=1 \mathrm{bar}$, liquid hourly space velocity (LHSV) $=3 \mathrm{~h}^{-1}$ (modified from Reference [34]).

\begin{tabular}{cccccc}
\hline $\begin{array}{c}\text { H-Beta Based Catalyst with } \\
\text { Pt-Pd Loading (wt \%/wt \%) }\end{array}$ & $\begin{array}{c}\text { Pd-Pt } \\
\mathbf{( 0 . 6 / 0 . 0 )}\end{array}$ & $\begin{array}{c}\text { Pd-Pt } \\
\mathbf{( 0 . 6 / 0 . 2 )}\end{array}$ & $\begin{array}{c}\text { Pd-Pt } \\
\mathbf{( 0 . 4 / 0 . 4 )}\end{array}$ & $\begin{array}{c}\text { Pd-Pt } \\
\mathbf{( 0 . 2 / 0 . 6 )}\end{array}$ & $\begin{array}{c}\text { Pd-Pt } \\
\mathbf{( 0 . 0 / 0 . 8 )}\end{array}$ \\
\hline Metal dispersion (\%) & 53 & 92 & 91 & 77 & 54 \\
Conversion (\%) & 54.9 & 77.0 & 77.6 & 74.2 & 64.8 \\
Isomerized selectivity (\%) & 80.4 & 91.2 & 92.9 & 92.3 & 7.7 \\
Cracked selectivity (\%) & 19.6 & 8.8 & 7.1 & 6.2 \\
\hline
\end{tabular}

A. de Lucas et al. [22] also focused on the influence of Pt-Pd metal loading and how the combination of these metals supported on catalysts based on agglomerated beta zeolite performed in the hydroisomerization of $n$-octane. For equal loadings, the metallic dispersion was higher in the case of platinum-based catalysts compared to palladium-based catalysts because their greater polarizability-due to the d electron configuration and larger atomic size-make Pt atoms less mobile than Pd atoms [36]. However, in the case of bimetallic Pt-Pd supported on agglomerated beta zeolite, 
the metal dispersion decreases with increasing palladium content owing to the interaction between palladium and platinum in bimetallic particles, as K. Lee et al. [37] and Pawelec et al. [38] demonstrated.

\subsubsection{Acid Zeolites}

In recent decades, many studies have been performed on the hydroisomerization of long-chain paraffins over zeolite catalysts thanks to their suitable acidity or hierarchical structures that combine microporous and mesoporous channel systems. In fact, due to their peculiar pore channel, zeolite-based catalysts are used to improve the degree of branching of product and decrease the tendency toward cracking reaction through the transition state selectivity (TSS) and product shape selectivity (PSS) effects. On the other hand, the acidity of the zeolite greatly influences the hydroisomerized yield. The acid strength distribution and acid site density both influence this yield, and the relation between metal sites and protonating sites is critical in determining the performance of the bifunctional catalysts. Many authors have concluded that weak or medium-strength Brønsted acid sites are responsible for promoting isomerized selectivity, whereas strong Brønsted acid and Lewis acid sites tend to promote cracking $[19,20,25,29,39,40]$. Hence, modifying the Brønsted acidity of the zeolite is essential to improve its hydroisomerization selectivity.

\section{Acid Sites}

The acidity of the zeolite is a crucial factor in determining the overall catalytic performance in the upgrading of vegetable oils to produce low-pour-point insulating and lubricating oils. The degree of acidity and the acid site types (Brønsted or Lewis) determine the degree to which the cracking or isomerization reaction is favored. Mériaudeau et al. [40] studied the performance of $1 \% \mathrm{Pt} / \mathrm{SAPO}-41$, $1 \% \mathrm{Pt} / \mathrm{SAPO}-31$, and $1 \% \mathrm{Pt} / \mathrm{SAPO}-11$ catalysts in $n$-octane hydroisomerization through a fixed-bed continuous flow reactor at $200-400{ }^{\circ} \mathrm{C}$ under atmospheric pressure. The catalytic activity decreased in increasing order of the amount and strength of acid sites: SAPO-41 > SAPO-11 > SAPO-31. However, the reaction rate was most strongly restricted by diffusion in the microporous channels of the SAPO-type zeolite. The low activity of the catalyst based on SAPO-31 zeolite resulted from the combined effect of its diffusion limitations and low acidity. Verma et al. [39] synthesized hierarchical mesoporous crystalline HZSM-5 zeolite catalysts in high-surface-area and low-surface-area types for the hydroconversion of algae and Jatropha seed oil to jet fuel. According to ${ }^{27} \mathrm{Al}$ MAS NMR analysis, the concentration of extra-framework Al present in the high-surface-area zeolite sample was higher than that in its low-surface-area counterpart, representing an increased number of Lewis acid sites in the former [41]. The former catalyst type also had more strong acid sites, favoring cracking and thus decreasing its isomerization selectivity. SAPO- 11 and ZSM-22 have been used widely in paraffin long-chain hydroisomerization catalysts because of their moderate acidity and straight channels of 10-membered rings. The drawback of this zeolite type is its lower acid site density at the pore mouths where the main isomerization occurs, according to the pore mouth and key-lock mechanism [42,43].

The acidity of zeolite can be also controlled by modifying its $\mathrm{Si} / \mathrm{Al}$ ratio by means of ion exchange or post-synthesis dealumination or desilication treatments, or by creating a siliceous border over the pore mouth of the channel system. The advantages of these tailoring methods are that they change both the total number of acidic sites and the density of electrons on the linking hydroxyl group, thereby changing the Brønsted acidity. Parma et al. [28] studied the effect of the zeolite $\mathrm{Si} / \mathrm{Al}$ ratio in the $\mathrm{Pt} / \mathrm{ZSM}-22$ catalyst system upon the branched isomer selectivity for $n$-hexadecane hydroisomerization (Table 4). Decreases in the total number of acid sites and in the number of Brønsted acid sites correspond to increases in the $\mathrm{Si} / \mathrm{Al}$ framework ratio. At the constant conversion level of $90 \%$, a catalyst having a lower $\mathrm{Si} / \mathrm{Al}$ ratio showed excellent selectivity and maximum isomer yield at lower reaction temperatures, $300-320^{\circ} \mathrm{C}$, compared to the reaction temperature range of $330-350{ }^{\circ} \mathrm{C}$, providing maximum isomer yield for a catalyst with a higher $\mathrm{Si} / \mathrm{Al}$ ratio. This result can be attributed to the mild Brønsted acidic strength of ZSM-22 zeolite, which favors isomerization over cracking at lower temperatures. Furthermore, relative to CAT-1 (having the Si/Al ratio of 30), CAT-2 (having the 
$\mathrm{Si} / \mathrm{Al}$ ratio of 45) has a lower reaction temperature that maximizes isomer yield, indicating that it has optimal acid function and metal site balance over the mouths of its zeolite pores.

Table 4. Acidity properties of H-ZSM-22 catalysts with various $\mathrm{Si} / \mathrm{Al}$ ratios and their reaction temperatures for obtaining 90\% conversion (modified from Reference [28]).

\begin{tabular}{|c|c|c|c|c|c|}
\hline Catalyst & $\begin{array}{l}\text { Bulk Si/Al } \\
\text { Ratio }\end{array}$ & $\begin{array}{l}\text { Total Acid Sites } \\
(\mu \mathrm{mol} \mathrm{NH} / \mathrm{g})\end{array}$ & $\begin{array}{l}\text { Brønsted Acid Sites } \\
\quad(\mu \mathrm{mol} \mathrm{NH} / \mathrm{g})\end{array}$ & $\begin{array}{l}\text { Lewis Acid Sites } \\
\left(\mu \mathrm{mol} \mathrm{NH}_{3} / \mathrm{g}\right)\end{array}$ & $\begin{array}{l}\text { Temperature Giving } \\
90 \% \text { Conversion }\left({ }^{\circ} \mathrm{C}\right)\end{array}$ \\
\hline CAT-1 & 30 & 217.5 & 177.1 & 40.4 & 320 \\
\hline CAT-2 & 45 & 146.6 & 127.5 & 19.1 & 305 \\
\hline CAT-3 & 60 & 115.0 & 104.3 & 10.7 & 330 \\
\hline CAT-4 & 90 & 78.8 & 71.3 & 7.5 & 350 \\
\hline
\end{tabular}

However, many authors have also stated that the number of acid centers of this zeolite type and their strength mainly determine their activity as hydroisomerization catalysts while having virtually no effect upon their selectivity, which instead depends more upon the structure and behavior of their pore systems.

\section{Pore Structure Effect}

Molecular sieve-based catalysts are used widely for hydroisomerization because of their narrow pores and the restricted access to and escape from their inner surfaces; the resulting behavior is termed pore mouth and key-lock catalysis [44-46]. The effects of the pore channels upon the metal/zeolite catalyst performance and the product distribution have been studied in depth in various efforts. The ZSM-22 zeolite, having TON (Theta-One)-framework topology, and SAPO-11, having the AEL (Aluminophosphates with sequence number ELeven)-framework structure consisting of one-dimensional channels each comprised of 10-membered rings, have been studied extensively for hydroisomerization $[19,25,29,30,32,45,47-50]$. Martens et al. [43,45,46,51] demonstrated that the specific confined space channels of these two zeolite structures allow their peculiar methyl branching selectivity and hinder decomposition reactions inside the pores. These authors studied the formations of monomethyl and dimethyl branching groups of long-chain paraffins from decane to tetracosane during hydroisomerization over the Pt/ZSM-22-bifunctional catalyst, based on the pore mouth and key-lock mechanism [46]. The maximal isomers yields were $77 \%-90 \%$, with the increase of mono- and multibranched isomer yields depending on the length of the paraffin chain. In detail, the mono- and multibranched isomer yields are $55 \%$ and $22 \%$ for $n$-C10 transformation, respectively, compared to over $80 \%$ and $70 \%$ in the case of higher carbon number paraffin chains as the initial material (n-C20, $n$-C22, and n-C24). Nghiem et al. [52] investigated Pt-based catalysts supported on ZSM and SAPO zeolite types with one-dimensional tubular and non-intersection medium pore structure for $n$-octane hydroisomerization. The catalyst performance and selectivity based on these zeolite types are shown in Table 5.

At $15 \%$ conversion, each of the listed catalysts has an isomerized selectivity of over $98 \%$, excepting those with large pore structures, ZSM-12 and SAPO-5, with $89 \%$ and $79 \%$ selectivities. Moreover, the maximum isomerized yields versus $n$-octane conversion are only $50 \%$ for ZSM- 12 and less than $30 \%$ for SAPO-5, whereas the other molecular sieves in this studied series gave $77-81 \mathrm{wt} \%$ isomerized yields.

Chi Kebin et al. [53] investigated the performance of platinum supported on ZSM-22/ZSM-23 zeolite mixtures as hydroisomerization catalysts. The ZSM-22/ZSM-23 zeolites were prepared to have a uniform needle-shaped particle size from spindle-shaped ZSM-22 and nest-shaped ZSM-23. These catalysts displayed unique molecular shape selectivity with a pore cross-section of $0.45 \times 0.55$ $\mathrm{nm}$ and had similar physical properties. At low conversions, the principal hydroisomerized products were monobranched isomers for all catalysts. This primary product transformed to multibranched isomers as secondary products when the degree of conversion was above $80 \%$, due to competitive adsorption on the catalyst surface favoring $n$-alkanes over monobranched isomers. In order of decreasing acidity, namely ZSM-23 > ZSM-22 > ZSM-22/ZSM-23, the hydrocracked products were 
decreasingly predominant at high conversions ( $>85 \%$ ), with $>35 \%, 27 \%$, and $19 \%$ yields over the respective supported platinum catalysts. However, as is common to all 10-membered ring zeolites, a drawback of these catalysts is that they hinder the hydrocracking reaction, thereby also inhibiting the generation of multibranched isomers due to increasing product diffusion limitations with increasing paraffin length. Actually, the hydroisomerization reaction would take place at the pore mouth while the carbon bears the positive charge of the stable carbenium ion localized inside the pore. This means that only the external surface of a ZSM-22 or SAPO-11 crystal contributes to the catalytic activity, whereas the remaining part of the crystal is catalytically inactive. Moreover, the diffusion limitations and confined access may also result in micropore blockage by large molecules or catalyst deactivation by means of coke deposition. Therefore, tailoring the pore architecture of zeolite-based catalysts to solve their diffusion limitations is highly desirable.

Table 5. Isomer selectivities of SAPO and ZSM zeolite types for $n$-octane hydroisomerization. Reaction conditions: $\mathrm{T}_{\mathrm{R}}=250{ }^{\circ} \mathrm{C}, \mathrm{H}_{2} / \mathrm{HC}=60$, conversion $\alpha=15 \%$, thermodynamic value $2-\mathrm{MeC}_{7} / 3-\mathrm{MeC}_{7}=$ 0.90 (modified from Reference [52]).

\begin{tabular}{|c|c|c|c|c|}
\hline Type of Zeolite & Dimensionality & Description & $\begin{array}{c}\text { Isomer Selectivity (wt \%) } \\
\text { at Conversion } \alpha=15 \%\end{array}$ & $\begin{array}{l}\text { Maximum Isomer } \\
\text { Yields (wt \%) }\end{array}$ \\
\hline SAPO-5 & 1-D & $\begin{array}{c}\text { 12-membered ring }(12-\mathrm{R}) \text { channels } \\
\text { each with pore opening } 0.7 \times 0.7 \\
\mathrm{~nm}\end{array}$ & 79 & $<30$ \\
\hline SAPO-31 & $1-\mathrm{D}$ & $\begin{array}{l}\text { 12-membered ring }(12-\mathrm{R}) \text { channels } \\
\text { each of } 0.54 \times 0.54 \mathrm{~nm} \text { diameter }\end{array}$ & 99 & 78 \\
\hline SAPO-11 & 1-D & $\begin{array}{l}10-\mathrm{R} \text { channels each with an elliptical } \\
\text { pore opening } 0.39 \times 0.64 \mathrm{~nm}\end{array}$ & 98 & 78 \\
\hline SAPO-41 & 1-D & $\begin{array}{l}\text { Elliptical } 10-\mathrm{R} \text { channels each } 0.43 \times \\
0.70 \text { in diameter }\end{array}$ & 99.5 & 81 \\
\hline ZSM-12 & 1-D & $\begin{array}{l}\text { 12-R channels each with pore } \\
\text { diameter } 0.55 \times 0.62 \mathrm{~nm}\end{array}$ & 89 & 50 \\
\hline ZSM-48 & $1-\mathrm{D}$ & $\begin{array}{l}\text { 10-R channels each with pore } \\
\text { diameter } 0.53 \times 0.56 \mathrm{~nm}\end{array}$ & 99 & 77 \\
\hline ZSM-22 & 1-D & $\begin{array}{l}\text { 10-R channels each with pore } \\
\text { diameter } 0.45 \times 0.55 \mathrm{~nm}\end{array}$ & 99.4 & 81 \\
\hline
\end{tabular}

Vandegehuchte et al. [54] investigated the effect of mixing a ZSM-22 zeolite ( $\mathrm{Si} / \mathrm{Al}=45)$ with a non-shape-selective $\mathrm{Y}$ zeolite $(\mathrm{Si} / \mathrm{Al}=2.6)$ in a Pt-based catalyst for $n-\mathrm{C}_{10}$ to $\mathrm{C}_{13}$ chain hydroisomerization via single-event microkinetic model simulations. The aim of this research was to optimize the synergy between primary monobranching on the more active ZSM-22 and secondary dibranching on $Y$. The best performance was obtained by using a zeolite mixture containing $75 \%$ ZSM-22. The maximal isomerized yields in this case reached $80 \%$ for $n-\mathrm{C}_{10}$ as the initial feed and $63 \%$ for a commercial mixture of $n-C_{10}$ to $C_{13}$ paraffin at the conversion level of $90 \%$.

A series of Pt/ZSM-22 catalysts with various siliceous degrees were synthesized for $n$-dodecane isomerization by Niu et al. [29]. Their work showed that the highly siliceous ZSM-22-based catalyst performed better than silica-alumina ZSM-22 analogues in terms of isomerized selectivity and hindering of the cracking reaction. The effect of Brønsted acidity upon isomerization was investigated by introducing acidic silanol groups. It was demonstrated that the acidic silanol group in pure silica zeolite is consider as a second kind of acid site, thereby improving the activity and isomer selectivity of the ZSM-22-based hydroisomerization catalyst when the amount of typical Brønsted acid sites is inadequate. In fact, the catalysis selectivity slightly increased with the Si/Al ratio; also, the selectivity of a catalyst based on siliceous ZSM- 22 was higher than that based on a silica-alumina mixture by $5 \%-7 \%$ over conversion, reaching the highest isomerized selectivity of $95.7 \%$ and maximum yield of $80.2 \%$.

In recent years, zeolites exhibiting hierarchical porosity, with their inherent microporous system and additional mesoporosity, have been investigated as alternative solutions for the abovementioned problems $[32,55,56]$. Mesoporosity can be induced by introducing intercrystalline mesopores 
into the nanoscale zeolite crystals or by creating a system of intracrystalline mesopores in the microporous channels (Figure 2). The advantage of such hierarchical systems is that they can integrate the shape selectivity of the intracrystalline micropores and the efficacious mass transfer of the mesoporous system because of their increased diffusivity and decreased diffusion path length [47]. Martens et al. [45] studied the impact of hierarchical ZSM-22-based catalyst upon the hydroisomerization reaction pathways of the $n$-decane, $n$-nonadecane, and pristane model molecules. Both conventional and hierarchized zeolites had the same platinum content and similar dispersion behavior. The efficiency of hierarchization is demonstrated by the increase of maximum isomer yields of $n$-decane hydroisomerization, reaching $82 \%$ versus the $67 \%$ of the conventional $\mathrm{Pt} / \mathrm{ZSM}-22$ catalyst. Similarly, in the case of $n$-nonadecane, the conventional ZSM-22-based catalyst showed a relatively high maximum yield of $88 \%$, which was further improved to $92 \%$ by hierarchization. Particularly, the formation of multibranched isomers was also enhanced. As mentioned above, the selectivity for multibranched isomers over this zeolite type was hindered; this selectivity was improved considerably by hierarchization. The maximum multibranch yields of $35 \%$ and $70 \%$ were observed at extremely high conversion levels in the cases of $n$-decane and $n$-nonadecane, respectively.

Furthermore, the greatest benefit of this hierarchical zeolite is its tendency to produce branched isomers having methyl groups near the center of the carbon chain; these are the most promising components to impart the desired low-temperature properties to vegetable oil-based insulating oils (Table 6).

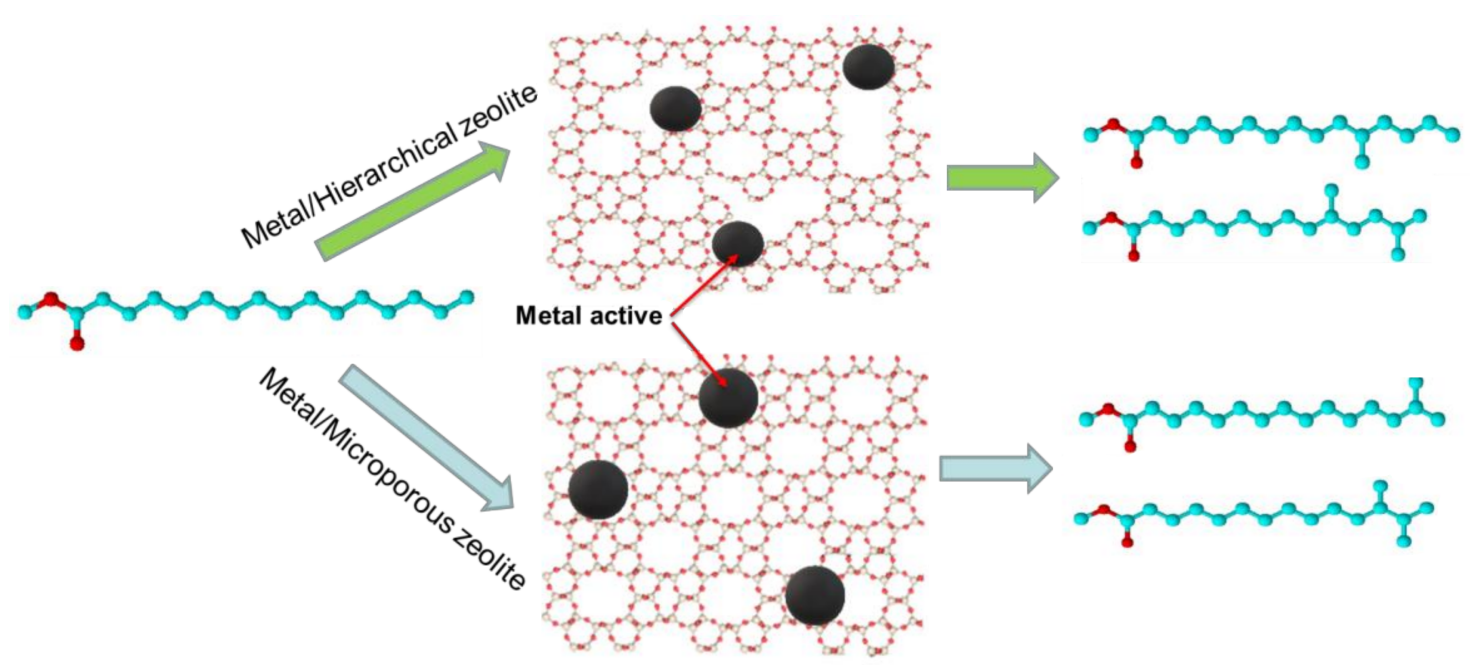

Figure 2. Schematic illustration of the effect of a hierarchical mesoporous ZSM-22 zeolite-based catalyst on hydroisomerization selectivity.

Table 6. Freezing points of some normal and isomethyl paraffins of various carbon numbers (modified from Reference $[57,58])$.

\begin{tabular}{cccc}
\hline \multirow{2}{*}{ Carbon Number } & \multicolumn{3}{c}{ Freezing Point, ${ }^{\circ} \mathbf{C}$} \\
\cline { 2 - 4 } & $\boldsymbol{n}$-Paraffin & 2-Methylparaffin & 5-Methylparaffin \\
\hline C12 & -10 & -46 & -70 \\
C13 & -5 & -26 & -69 \\
C16 & 18 & -10 & -31 \\
C18 & 28 & 6 & -20 \\
C20 & 37 & 18 & -7 \\
\hline
\end{tabular}

For $n$-decane, initially, both conventional and hierarchical ZSM-22 favor the formation of 2-methylnonane and hinder the formation of 4- and 5-methylnonanes. As the isomer yields approach their maximums, the positional distribution of methylnonanes reaches an equilibrium composition. 
The proportion of 2- over 5-methyl-nonane generation at $5 \%$ conversion is termed the refined constraint index $\mathrm{CI}^{\circ}$, reflecting the pore width [59]. After hierarchization, the $\mathrm{CI}^{\circ}$ drops from 14.5 to 8.0, which is still in the range of the 10- $\mathrm{R}$ zeolite $\left(\mathrm{CI}^{\circ}>2.2\right)$ [59]. The efficient catalytic hydroisomerization observed for the hierarchized catalysts can be explained by the rearrangement of the spatial Brønsted acidity distribution. Namely, hierarchization reduces the number of acid sites in the micropores, thereby limiting the hydrocracking reaction. At the same time, it increases the number of acid sites at pore mouths, thereby favoring the isomerization reaction. This argument is also investigated in research by Tao et al. [32], which focused on the preparation of hierarchical SAPO-11 zeolite by means of a dry-gel conversion method with 3-(trimethoxysilyl) propyl]octadecyldimethyl ammonium chloride (TPOAC) templating and its application for $n$-dodecane hydroisomerization. Besides the integration of mesopores into microporous zeolite, acidity tuning was also carried out to improve the catalysis performance of hierarchical zeolite. It is mostly believed that the medium and strong acidity of Brønsted acid sites plays a crucial role in skeletal isomerization. Notably, although the number of Brønsted acid sites of hierarchical SAPO-11 is less than that of conventional SAPO-11, the hydroisomerization conversion over $\mathrm{Pt} /$ hierarchical SAPO-11 is moderately higher than that over its nonhierarchical counterpart. This is likely because of the greater availability of pore mouths in the case of the hierarchical SAPO-11 zeolite-based catalyst. Similarly, the uniform intercrystalline mesopores of the hierarchical structure and the increased number of medium-acidity sites present owing to water content control can enhance the diffusion of the multibranched isomer out of the micropores before cracking occurs, thereby leading to higher yields of multibranched isomers.

\subsubsection{Metal/Acid Site Balance}

The interactivity between metal and zeolite plays an important role in bifunctional hydroisomerization catalysts. Mendes et al. [31] investigated the role of hydrogenating (metal)/acid function balance upon isomerized selectivity, representing this balance by the ratio between the number of accessible metal atoms $\left(\mathrm{n}_{\mathrm{Pt}}\right)$ and the number of aluminum atoms $\left(\mathrm{n}_{\mathrm{Al}}\right)$ that form the negative charge $\left(\mathrm{AlO}_{4}{ }^{-}\right)$in the zeolite's framework. Platinum-based catalysts supported on HUSY and HBEA zeolites showed increasing yields of iso- $\mathrm{C}_{16}$ at low $\mathrm{n}_{\mathrm{Pt}} / \mathrm{n}_{\mathrm{Al}}$ values, followed by a plateau in yield for $\mathrm{n}_{\mathrm{Pt}} / \mathrm{n}_{\mathrm{Al}}$ values higher than 0.01 and 0.02 , respectively. The balance between dehydrogenating sites and acid sites is indicated by the maximum yield of iso- $\mathrm{C}_{16}$. Increasing the metal loading (Table 7) causes dehydrogenation to take place much faster than acid-catalyzed steps, and thus the isoalkenes formed will be promptly hydrogenated, favoring isomerization rather than cracking.

Table 7. Metal dispersions, number of accessible metal atoms, metal/acid site ratios, corresponding turnover frequency $\left(\mathrm{TOF}_{\mathrm{Al}}\right)$ at $480 \mathrm{~K}$, and maximal isomer yields estimated acid site concentrations for selected catalysts with various Pt loadings (modified from Reference [31]).

\begin{tabular}{|c|c|c|c|c|c|c|}
\hline Catalyst & $\mathrm{n}_{\mathrm{Al}}(\mu \mathrm{mol} / \mathrm{g})$ & Dispersion (\%) & $\mathrm{n}_{\mathrm{Pt}}(\mu \mathrm{mol} / \mathrm{g})$ & $\mathbf{n}_{\mathrm{Pt}} / \mathbf{n}_{\mathrm{Al}}$ & $\begin{array}{c}\text { TOF }_{\mathrm{Al}} \text { at } 480 \mathrm{~K} \\
\left(10^{3} \mathrm{~s}^{-1}\right)\end{array}$ & $\begin{array}{c}\text { Maximal i-C } 16 \\
\text { yield }(\%)\end{array}$ \\
\hline $0.1 \% \mathrm{Pt} / \mathrm{HUSY}$ & 820 & 53 & 3 & 0.003 & 1.6 & 46.5 \\
\hline $0.4 \% \mathrm{Pt} / \mathrm{HUSY}$ & 820 & 53 & 11 & 0.013 & 2.1 & 59.3 \\
\hline $0.7 \% \mathrm{Pt} / \mathrm{HUSY}$ & 820 & 52 & 19 & 0.023 & 1.6 & 62.1 \\
\hline $0.1 \% \mathrm{Pt} / \mathrm{HBEA}$ & 840 & 45 & 2 & 0.003 & 3.0 & 29.2 \\
\hline $0.4 \% \mathrm{Pt} / \mathrm{HBEA}$ & 840 & 43 & 9 & 0.010 & 4.0 & 63.5 \\
\hline 1\%Pt/HBEA & 840 & 37 & 19 & 0.023 & 4.7 & 67.3 \\
\hline
\end{tabular}

Similar dependences were also reported by Batalha et al. [60], who demonstrated that at low $\mathrm{C}_{\mathrm{Pt}} / \mathrm{C}_{\mathrm{H}+}$ values the rate-determining step of $n-\mathrm{C}_{16}$ hydroisomerization over Pt/alumina-HBEA is the hydrogenation/dehydrogenation step over the metallic phase, and at high $\mathrm{C}_{\mathrm{Pt}} / \mathrm{C}_{\mathrm{H}+}$ values it is the rearrangement of cycloprotonated intermediates over the acidic sites. On the $\mathrm{Pd} / \mathrm{SAPO}-11$-based catalyst [30], the optimal $\mathrm{C}_{\mathrm{Pd}} / \mathrm{C}_{\mathrm{H}+}$ ratio is in the range of $0.09-0.27$, corresponding to $0.1-0.3 \mathrm{wt} \% \mathrm{Pd}$ loadings. This catalyst can be considered as an ideal hydroisomerization catalyst, showing excellent synergy between the metal Pd sites and Brønsted acid sites. The highest isomer 
selectivity of $89.9 \%$ at the conversion level of $90.8 \%$ was observed in $n$-decane transformation over the $0.3 \% \mathrm{Pd} / \mathrm{SAPO}-11$ catalyst. For $\mathrm{C}_{\mathrm{Pd}} / \mathrm{C}_{\mathrm{H}+}$ ratios higher than 0.47 , the increasing agglomeration of $\mathrm{Pd}$ particles blocks the pore channel and pore mouth of the SAPO-11 structure, resulting in suppressed diffusion of the branched isomers and excessive cracking.

\section{Blending Process}

The blending of alternative fluids has been investigated as a means to improve the properties of vegetable oil-based insulating oils [61-64]. Usman et al. [61] studied several characteristics of a mixture of soybean and palm kernel oil for its suitability as an insulator fluid in power transformers. Although such blends have very high flash points $\left(>234^{\circ} \mathrm{C}\right)$ and economic and environmental advantages, these blended oils do not show any synergy in improving physical properties such as pour point and viscosity, which are dependent upon the degree of saturation. A study by Bertrand et al. [62] demonstrated the ability to decrease the pour point and viscosity of vegetable oil-based insulating oil by mixing oleic rapeseed oil and fatty monoesters in a $1: 1$ ratio and adding $0.3 \%$ of the inhibitor di-tert-butyl-para-cresol. The resulting blend showed the pour point of $-30{ }^{\circ} \mathrm{C}$ and the kinetic viscosity at $40{ }^{\circ} \mathrm{C}$ of $17 \mathrm{~mm}^{2} / \mathrm{s}$.

Using an additive to reduce the pour points and to increase the oxidation stability of natural esters is also an efficient method, and has been applied in electric industrial processing. To improve the low-temperature properties, polymer additives called pour point depressants (PPDs) can be used to reduce the pour point. There is adequate literature on the efficacy of various PPDs based on polymers such as modified carboxyl polymers, acrylate polymers, nitrogen-based acrylate polymers, and methylene-linked aromatic components. Unfortunately, the use of such PPDs can be limited by their nonbiodegradability. Antioxidant additives that have been applied to vegetable oil-based insulating oil include phenolic compounds such as butylated hydroxyanisole, butylated hydroxytoluene, tert-butylhydroquinone, and propyl gallate. Their role is to slow natural oxidation by reacting with free radicals to form stable compounds that do not rapidly react with oxygen. Many works have demonstrated the effects of such additives upon the oxidation stability of insulators [48,65-68]. Nonetheless, the economic costs and the human health and environmental impacts of these additives hinder their application $[69,70]$.

\section{Conclusions}

Vegetable oils can be used as the feedstock of insulating oils for electric transformers thanks to their environmental benefits such as low ecotoxicity, high biodegradability, and replacement of petroleum oils. The main challenges in applying vegetable oils as insulating transformer oils are their poor low-temperature properties and low oxidation stabilities; owing to their saturated and unsaturated fatty acid esters, vegetable oils' pour points and viscosities are higher than those of mineral oils.

The hydroisomerization of saturated and unsaturated long-chain normal paraffins to form branched isomers is a promising pathway for upgrading vegetable oil-based insulating oils, even for the bio-based lubricant with a similar composition. The processing efficiency is determined by the catalyst used. Zeolites are of interest as catalyst supports for isomerization upgrading because of their microporous channels and lack of large voids, making them more selective for the hydroisomerization of long-chain paraffins. Furthermore, the diffusion limitations of zeolites can be suppressed by means of methods that form hierarchical mesoporous/microporous structures.

Although many reports have advanced our knowledge on the role of the metal phase and Brønsted acid sites, as well as the effects of the pore structures of many kind of zeolites upon activity and selectivity, a more detailed understanding of the metal/acid functional balance of noble metal/zeolite catalysts is needed to widen their application and decrease their cost. 
Acknowledgments: This research was supported by the Basic Science Research Program (2017R1A2B4007648) and the C1 Gas Refinery Program (2015M3D3A1A01064882) through the National Research Foundation of Korea (NRF), funded by the Ministry of Science and ICT.

Author Contributions: Dieu-Phuong Phan prepared a draft of the manuscript. Eun Yeol Lee coordinated the study and finalized the manuscript. All authors read and approved the manuscript.

Conflicts of Interest: The authors declare no conflicts of interest.

\section{References}

1. Sierota, A.; Rungis, J. Electrical insulating oils. I. Characterization and pre-treatment of new transformer oils. IEEE Electr. Insul. Mag. 1995, 11, 8-20. [CrossRef]

2. Rouse, T.O. Mineral insulating oil in transformers. IEEE Electr. Insul. Mag. 1998, 14, 6-16. [CrossRef]

3. Miller, R.E. Silicone Transformer Liquid: Use, Maintenance, and Safety. IEEE Trans. Ind. Appl. 1981, IA-17, 463-468. [CrossRef]

4. Dolata, B.; Borsi, H.; Gockenbach, E. New synthetic ester fluid for the insulation of liquid immersed transformers. In Proceedings of the Conference Record of the 2006 IEEE International Symposium on Electrical Insulation, Toronto, ON, Canada, 11-14 June 2006; pp. 534-537.

5. Nagashree, A.N.; Champa, V.; Sumangala, B.V.; Nagabhushana, G.R. Suitability of natural vegetable seed oil as liquid dielectric coolant in an insulation system. In Proceedings of the 2015 International Conference on Emerging Research in Electronics, Computer Science and Technology (ICERECT), Mandya, India, 17-19 December 2015; pp. 429-434.

6. McShane, C.P. Relative properties of the new combustion-resist vegetable-oil-based dielectric coolants for distribution and power transformers. IEEE Trans. Ind. Appl. 2001, 37, 1132-1139. [CrossRef]

7. Fernández, I.; Ortiz, A.; Delgado, F.; Renedo, C.; Pérez, S. Comparative evaluation of alternative fluids for power transformers. Electr. Power Syst. Res. 2013, 98, 58-69. [CrossRef]

8. Ramos, M.J.; María Fernández, C.; Casas, A.; Rodriguez, L.; Pérez, Á. Influence of fatty acid composition of raw materials on biodiesel properties. Bioresour. Technol. 2008, 100, 261-268. [CrossRef] [PubMed]

9. Al-Eshaikh, M.A.; Qureshi, M.I. Evaluation of Food Grade Corn Oil for Electrical Applications. Int. J. Green Energy 2012, 9, 441-455. [CrossRef]

10. Rafiq, M.; Lv, Y.Z.; Zhou, Y.; Ma, K.B.; Wang, W.; Li, C.R.; Wang, Q. Use of vegetable oils as transformer oils-A review. Renew. Sustain. Energy Rev. 2015, 52, 308-324. [CrossRef]

11. Xu, Y.; Qian, S.; Liu, Q.; Wang, Z.D. Oxidation stability assessment of a vegetable transformer oil under thermal aging. IEEE Trans. Dielectr. Electr. Insul. 2014, 21, 683-692. [CrossRef]

12. Bertrand, Y.; Hoang, L.C. Vegetal oils as substitute for mineral oils. In Proceedings of the 7th International Conference on Properties and Applications of Dielectric Materials (Cat. No. 03CH37417), Nagoya, Japan, 1-5 June 2003; Volume 492, pp. 491-494.

13. Jie, D.; Wang, Z.D.; Dyer, P.; Darwin, A.W.; James, I. Investigation of the impregnation of cellulosic insulations by ester fluids. In Proceedings of the 2007 Annual Report-Conference on Electrical Insulation and Dielectric Phenomena, Vancouver, BC, Canada, 14-17 October 2007; pp. 588-591.

14. Ngo, H.L.; Nuñez, A.; Lin, W.; Foglia, T.A. Zeolite-catalyzed isomerization of oleic acid to branched-chain isomers. Eur. J. Lipid Sci. Technol. 2007, 109, 214-224. [CrossRef]

15. Abhari, R.; Roth, E.G.; Havlik, P.Z.; Tomhnson, H.L. Bio-Based Synthetic Fluids. U.S. Patent 8,969,259 B2, 3 March 2015.

16. Reaume, S.; Ellis, N. Use of Isomerization and Hydroisomerization Reactions to Improve the Cold Flow Properties of Vegetable Oil Based Biodiesel. Energies 2013, 6, 619. [CrossRef]

17. Reaume, S.J.; Ellis, N. Synergistic Effects of Skeletal Isomerization on Oleic and Palmitic Acid Mixtures for the Reduction in Cloud Point of Their Methyl Esters. Energy Fuels 2012, 26, 4514-4520. [CrossRef]

18. Weitkamp, J. Isomerization of long-chain n-alkanes on a Pt/CaY zeolite catalyst. Ind. Eng. Chem. Prod. Res. Dev. 1982, 21, 550-558. [CrossRef]

19. Höchtl, M.; Jentys, A.; Vinek, H. Alkane conversion over Pd/SAPO molecular sieves: Influence of acidity, metal concentration and structure. Catal. Today 2001, 65, 171-177. [CrossRef] 
20. Choudhury, I.R.; Hayasaka, K.; Thybaut, J.W.; Laxmi Narasimhan, C.S.; Denayer, J.F.; Martens, J.A.; Marin, G.B. Pt/H-ZSM-22 hydroisomerization catalysts optimization guided by Single-Event MicroKinetic modeling. J. Catal. 2012, 290, 165-176. [CrossRef]

21. Zhang, S.; Zhang, Y.; Tierney, J.W.; Wender, I. Anion-modified zirconia: Effect of metal promotion and hydrogen reduction on hydroisomerization of n-hexadecane and Fischer-Tropsch waxes. Fuel Process. Technol. 2001, 69, 59-71. [CrossRef]

22. De Lucas, A.; sánchez, P.; Dorado, F.; Ramos, M.J.; Valverde, J. Effect of the metal loading in the hydroisomerization of n-octane over beta agglomerated zeolite based catalysts. Appl. Catal. A Gen. 2005, 294, 215-225. [CrossRef]

23. Akhmedov, V.M.; Al-Khowaiter, S.H. Recent Advances and Future Aspects in the Selective Isomerization of High n-Alkanes. Catal. Rev. 2007, 49, 33-139. [CrossRef]

24. Martens, J.A.; Verboekend, D.; Thomas, K.; Vanbutsele, G.; Gilson, J.P.; Perez-Ramirez, J. Hydroisomerization of emerging renewable hydrocarbons using hierarchical Pt/H-ZSM-22 catalyst. ChemSusChem 2013, 6, 421-425. [CrossRef] [PubMed]

25. Yang, J.; Kikhtyanin, O.V.; Wu, W.; Zhou, Y.; Toktarev, A.V.; Echevsky, G.V.; Zhang, R. Influence of the template on the properties of SAPO-31 and performance of Pd-loaded catalysts for n-paraffin isomerization. Microporous Mesoporous Mater. 2012, 150, 14-24. [CrossRef]

26. Guisnet, M. “Ideal” bifunctional catalysis over Pt-acid zeolites. Catal. Today 2013, 218, 123-134. [CrossRef]

27. Coonradt, H.L.; Garwood, W.E. Mechanism of Hydrocracking. Reactions of Paraffins and Olefins. Ind. Eng. Chem. Process Des. Dev. 1964, 3, 38-45. [CrossRef]

28. Parmar, S.; Pant, K.K.; John, M.; Kumar, K.; Pai, S.M.; Newalkar, B.L. Hydroisomerization of Long Chain n-Paraffins over Pt/ZSM-22: Influence of Si/Al Ratio. Energy Fuels 2015, 29, 1066-1075. [CrossRef]

29. Niu, P.; Xi, H.; Ren, J.; Lin, M.; Wang, Q.; Jia, L.; Hou, B.; Li, D. High selectivity for n-dodecane hydroisomerization over highly siliceous ZSM-22 with low Pt loading. Catal. Sci. Technol. 2017, 7, 5055-5068. [CrossRef]

30. Song, X.; Bai, X.; Wu, W.; Kikhtyanin, O.V.; Zhao, A.; Xiao, L.; Su, X.; Zhang, J.; Wei, X. The effect of palladium loading on the catalytic performance of Pd/SAPO-11 for n-decane hydroisomerization. Mol. Catal. 2017, 433, 84-90. [CrossRef]

31. Mendes, P.S.F.; Mota, F.M.; Silva, J.M.; Ribeiro, M.F.; Daudin, A.; Bouchy, C. A systematic study on mixtures of Pt/zeolite as hydroisomerization catalysts. Catal. Sci. Technol. 2017, 7, 1095-1107. [CrossRef]

32. Tao, S.; Li, X.L.; Lv, G.; Wang, C.X.; Xu, R.S.; Ma, H.J.; Tian, Z.J. Highly mesoporous SAPO-11 molecular sieves with tunable acidity: Facile synthesis, formation mechanism and catalytic performance in hydroisomerization of n-dodecane. Catal. Sci. Technol. 2017, 7, 5775-5784. [CrossRef]

33. Snåre, M.; Kubičková, I.; Mäki-Arvela, P.; Eränen, K.; Murzin, D.Y. Heterogeneous Catalytic Deoxygenation of Stearic Acid for Production of Biodiesel. Ind. Eng. Chem. Res. 2006, 45, 5708-5715. [CrossRef]

34. Bauer, F.; Karsten, F.; Marko, B.; Wolf-Dietrich, E.; Thomas, K.; Roger, G. Hydroisomerization of Long-Chain Paraffins over Nano-Sized Bimetallic Pt-Pd/H-Beta Catalysts. Catal. Sci. Technol. 2014, 4, 4045-4054. [CrossRef]

35. Blomsma, E.; Martens, J.A.; Jacobs, P.A. Isomerization and Hydrocracking of Heptane over Bimetallic Bifunctional PtPd/H-Beta and PtPd/USY Zeolite Catalysts. J. Catal. 1997, 165, 241-248. [CrossRef]

36. Sachtler, M.H.; Zhang, Z. Zeolite-Supported Transition Metal Catalysts. Adv. Catal. 1993, 39, 129-220.

37. Lee, J.-K.; Rhee, H.-K. Sulfur tolerance of zeolite beta-supported Pd-Pt catalysts for the isomerization of n-hexane. J. Catal. 1998, 177, 208-216. [CrossRef]

38. Pawelec, B.; Mariscal, R.; Navarro, R.M.; van Bokhorst, S.; Rojas, S.; Fierro, J.L.G. Hydrogenation of aromatics over supported Pt-Pd catalysts. Appl. Catal. A Gen. 2002, 225, 223-237. [CrossRef]

39. Verma, D.; Kumar, R.; Rana, B.S.; Sinha, A.K. Aviation fuel production from lipids by a single-step route using hierarchical mesoporous zeolites. Energy Environ. Sci. 2011, 4, 1667-1671. [CrossRef]

40. Mériaudeau, P.; Tuan, V.A.; Nghiem, V.T.; Lai, S.Y.; Hung, L.N.; Naccache, C. SAPO-11, SAPO-31, and SAPO-41 Molecular Sieves: Synthesis, Characterization, and Catalytic Properties inn-Octane Hydroisomerization. J. Catal. 1997, 169, 55-66. [CrossRef]

41. Li, S.; Zheng, A.; Su, Y.; Zhang, H.; Chen, L.; Yang, J.; Ye, C.; Deng, F. Brønsted/Lewis Acid Synergy in Dealuminated HY Zeolite: A Combined Solid-State NMR and Theoretical Calculation Study. J. Am. Chem. Soc. 2007, 129, 11161-11171. [CrossRef] [PubMed] 
42. Maesen, T.L.M.; Schenk, M.; Vlugt, T.J.H.; Jonge, J.P.d.; Smit, B. The Shape Selectivity of Paraffin Hydroconversion on TON-, MTT-, and AEL-Type Sieves. J. Catal. 1999, 188, 403-412. [CrossRef]

43. Claude, M.C.; Martens, J.A. Monomethyl-Branching of Long n-Alkanes in the Range from Decane to Tetracosane on Pt/H-ZSM-22 Bifunctional Catalyst. J. Catal. 2000, 190, 39-48. [CrossRef]

44. Weisz, P.B.; Frilette, V.J.; Maatman, R.W.; Mower, E.B. Catalysis by crystalline aluminosilicates II. Molecular-shape selective reactions. J. Catal. 1962, 1, 307-312. [CrossRef]

45. Martens, J.A.; Verboekend, D.; Thomas, K.; Vanbutsele, G.; Pérez-Ramírez, J.; Gilson, J.-P. Hydroisomerization and hydrocracking of linear and multibranched long model alkanes on hierarchical Pt/ZSM-22 zeolite. Catal. Today 2013, 218-219, 135-142. [CrossRef]

46. Martens, J.A.; Souverijns, W.; Verrelst, W.; Parton, R.F.; Froment, G.; Pierre, J. Selective Isomerization of Hydrocarbon Chains on External Surfaces of Zeolite Crystals. Angew. Chem. Int. Ed. 1995, 34, 2528-2530. [CrossRef]

47. Wei, Y.; Parmentier, T.E.; de Jong, K.P.; Zecevic, J. Tailoring and visualizing the pore architecture of hierarchical zeolites. Chem. Soc. Rev. 2015, 44, 7234-7261. [CrossRef] [PubMed]

48. Ullah, J.; Hamayoun, M.; Ahmad, T.; Ayub, M.; Zafarullah, M. Effect of light, natural and synthetic antioxidants on stability of edible oil and fats. Asian J. Plant Sci. 2003, 2, 1192-1194.

49. Wang, Y.; Tao, Z.; Wu, B.; Xu, J.; Huo, C.; Li, K.; Chen, H.; Yang, Y.; Li, Y. Effect of metal precursors on the performance of Pt/ZSM-22 catalysts for n-hexadecane hydroisomerization. J. Catal. 2015, 322, 1-13. [CrossRef]

50. Shi, Y.; Cao, Y.; Duan, Y.; Chen, H.; Chen, Y.; Yang, M.; Wu, Y. Upgrading of palmitic acid to iso-alkanes over bi-functional Mo/ZSM-22 catalysts. Green Chem. 2016, 18, 4633-4648. [CrossRef]

51. Claude, M.C.; Vanbutsele, G.; Martens, J.A. Dimethyl Branching of Long n-Alkanes in the Range from Decane to Tetracosane on Pt/H-ZSM-22 Bifunctional Catalyst. J. Catal. 2001, 203, 213-231. [CrossRef]

52. Nghiem, V.T.; Sapaly, G.; Mériaudeau, P.; Naccache, C. Monodimensional tubular medium pore molecular sieves for selective hydroisomerisation of long chain alkanes: n-octane reaction on ZSM and SAPO type catalysts. Top. Catal. 2000, 14, 131-138. [CrossRef]

53. Chi, K.B.; Zhao, Z.; Tian, Z.J.; Hu, S.; Yan, L.J.; Li, T.S.; Wang, B.C.; Meng, X.B.; Gao, S.B.; Tan, M.W.; et al. Hydroisomerization performance of platinum supported on ZSM-22/ZSM-23 intergrowth zeolite catalyst. Pet. Sci. 2013, 10, 242-250. [CrossRef]

54. Vandegehuchte, B.D.; Thybaut, J.W.; Martens, J.A.; Marin, G.B. Maximizing n-alkane hydroisomerization: The interplay of phase, feed complexity and zeolite catalyst mixing. Catal. Sci. Technol. 2015, 5, 2053-2058. [CrossRef]

55. Liu, Y.; Qu, W.; Chang, W.; Pan, S.; Tian, Z.; Meng, X.; Rigutto, M.; Made, A.v.d.; Zhao, L.; Zheng, X.; et al. Catalytically active and hierarchically porous SAPO-11 zeolite synthesized in the presence of polyhexamethylene biguanidine. J. Colloid Interface Sci. 2014, 418, 193-199. [CrossRef] [PubMed]

56. Liu, Z.; Liu, L.; Song, H.; Wang, C.; Xing, W.; Komarneni, S.; Yan, Z. Hierarchical SAPO-11 preparation in the presence of glucose. Mater. Lett. 2015, 154, 116-119. [CrossRef]

57. Krár, M.; Kasza, T.; Kovács, S.; Kalló, D.; Hancsók, J. Bio gas oils with improved low temperature properties. Fuel Process. Technol. 2011, 92, 886-892. [CrossRef]

58. Knothe, G.; Dunn, R. A Comprehensive Evaluation of the Melting Points of Fatty Acids and Esters Determined by Differential Scanning Calorimetry. J. Am.Oil Chem. Soc. 2009, 86, 843-856. [CrossRef]

59. Martens, J.A.; Jacobs, P.A. The potential and limitations of the n-decane hydroconversion as a test reaction for characterization of the void space of molecular sieve zeolites. Zeolites 1986, 6, 334-348. [CrossRef]

60. Batalha, N.; Pinard, L.; Bouchy, C.; Guillon, E.; Guisnet, M. n-Hexadecane hydroisomerization over Pt-HBEA catalysts. Quantification and effect of the intimacy between metal and protonic sites. J. Catal. 2013, 307, 122-131. [CrossRef]

61. Usman, M.A.; Olanipekun, O.O.; Henshaw, U.T. A Comparative Study of Soya Bean Oil and Palm Kernel Oil as Alternatives to Transformer Oil. J. Emerg. Trends Eng. Appl. Sci. 2012, 3, 33-37.

62. Bertrand, Y.; Lauzevis, P. development of a low viscosity insulating liquid based on natural esters for distribution transformers. In Proceedings of the 22nd International Conference on Electricity Distribution, Stockholm, Sweden, 10-13 June 2013; p. 382. 
63. Suwarno; Darma, I.S. Dielectric properties of mixtures between mineral oil and natural ester. In Proceedings of the 2008 International Symposium on Electrical Insulating Materials (ISEIM 2008), Mie, Japan, 7-11 September 2008; pp. 514-517.

64. Qiu, H.B.S.W. Blended Oil Compositions Useful as Dielectric Fluid Compositions and Methods of Preparing Same. U.S. Patent US20140131634A1, 13 November 2012.

65. Dunn, R.O. Effect of antioxidants on the oxidative stability of methyl soyate (biodiesel). Fuel Process. Technol. 2005, 86, 1071-1085. [CrossRef]

66. Jung, M.Y.; Min, D.B. Effects of oxidized $\alpha-, \gamma$ - and $\delta$-tocopherols on the oxidative stability of purified soybean oil. Food Chem. 1992, 45, 183-187. [CrossRef]

67. Ruger, C.W.; Klinker, E.J.; Hammond, E.G. Abilities of some antioxidants to stabilize soybean oil in industrial use conditions. J. Am. Oil Chem. Soc. 2002, 79, 733-736. [CrossRef]

68. Kumar, S.S.; Iruthayarajan, M.W.; Bakrutheen, M.; Kannan, S.G. Effect of antioxidants on critical properties of natural esters for liquid insulations. IEEE Trans. Dielectr. Electr. Insul. 2016, 23, 2068-2078. [CrossRef]

69. Khanahmadi, M.; Janfeshan, K. Study on Antioxidation Property of Ferulago angulata Plant. Asian J. Plant Sci. 2006, 5, 521-526.

70. Morteza-Semnani, K.; Saeedi, M.; Shahani, S. Antioxidant activity of the methanolic extracts of some species of Phlomis and Stachys on sunflower oil. Afr. J. Biotechnol. 2006, 5, 2428-2432.

(C) 2018 by the authors. Licensee MDPI, Basel, Switzerland. This article is an open access article distributed under the terms and conditions of the Creative Commons Attribution (CC BY) license (http://creativecommons.org/licenses/by/4.0/). 